\title{
Knowledge Sharing Leveraging New Product Development Activities to Derive Enhanced Business Performance: Mixed Method Study
}

\author{
T.T. Huang ${ }^{1}$, R.A. Stewart ${ }^{1}$, and L. Chen ${ }^{1}$ \\ ${ }^{1}$ Griffith School of Engineering, Griffith University, Gold Coast, Australia \\ (andrew.huang@griffith.edu.au, r.stewart@griffith.edu.au, 1.chen@griffith.edu.au)
}

\begin{abstract}
Knowledge has been widely recognised as a determinant of business performance. Business capabilities require an effective share of resource and knowledge. Specifically, knowledge sharing (KS) between different companies and departments can improve manufacturing processes since intangible knowledge plays an enssential role in achieving competitive advantage. This paper presents a mixed method research study into the impact of KS on the effectiveness of new product development (NPD) in achieving desired business performance (BP). Firstly, an empirical study utilising moderated regression analysis was conducted to test whether and to what extent KS has leveraging power on the relationship between NPD and BP constructs and variables. Secondly, this empirically verified hypothesis was validated through explanatory case studies involving two Taiwanese manufacturing companies using a qualitative interaction term pattern matching technique. The study provides evidence that knowledge sharing and management activities are essential for deriving competitive advantage in the manufacturing industry.
\end{abstract}

Keywords - Knowledge sharing, Business performance, New product development.

\section{INTRODUCTION}

Rapidly advancing information technologies and fierce global competition has forced manufacturers to seek ways to sustain their competitiveness. Competitive advantage with be held by those companies who are able to instil collaborative cooperation, introduce product to market ahead of their competitors and allocate intangible resource and knowledge to the right people at the right time [1]. While Asia has become the manufacturing centre in recent years, Taiwanese manufacturers have focused efforts in the IT hardware market. Moreover, they are streamlining business activities and strategies, especially in innovative product development practices, continuous process improvement and operations management [2].

Considerably shortened product life cycles have been emphasized, since effective and efficient NPD activities are expected to result in shorter and more cost effective design practices as well as quicker time to customer/market $[3,4]$. In general, three NPD practices are often highlighted, including: design simplification (i.e. component reduction/standardisation); modular product design; and design for quality, assembly and manufacturability. The continuous application and improvement of these practices typically results in lower rates of workmanship and fewer defective products, which consequently reduce cost, improve production efficiency and shortens the overall product development time [5]. In addition, effective product design and development processes have long been recognised as an important market leadership tool by successful companies in competitive industries [2].

Typically, NPD activities in the electronic manufacturing sector require a high proportion of company resources such as budget and manpower. Manufacturers and their suppliers are increasingly intertwined in the operational process; thus the more active the KS practices, the better the business outcomes [6]. In addition, sharing design resource and knowledge can increase product development capacity and reduce both the duration and costs associated with a particular development cycle [5]. Therefore, KS is the a key enabler that leverages NPD to achieve the desired performance more effectively $[7,8]$. Studies support the view that a successful company must constantly create or reuse knowledge through management and technology innovation [9]. Moreover, manufacturers are able to create synergy through sharing and harnessing internal resource and knowledge as well as absorbing external knowledge and up-to-date technology [10]. Therefore, knowledge-based assets (e.g., intellectual capital) have become a primary norm of organisational competence and the key to superior performance [7]. In short, through reusing, refining and sharing information and knowledge, a company will improve business practices which will ultimately lead to advanced competitive advantage and performance [11].

\section{CONCEPTUAL MODEL DEVELOPMENT}

Given the essential role of NPD in manufacturing companies, this study attempted to shed some light on this issue within the context of Taiwan electronic manufacturers, and aims to provide answers for the two overarching research objectives: (1) confirm the previously identified empirical relationships between KS, NPD and BP; and more definitively (2) investigate whether and to what extent KS leverages heightened effectiveness in NPD activities to achieve higher level of BP. Based on the review of literature, three hypotheses (graphically illustrated in Fig. 1) were formulated to 
facilitate the investigation of the issues raised by the overarching research objectives:

- H1-1: KS is positively associated with BP.

- H2-1: NPD is positively associated with BP.

- H2-2: The higher the KS, the stronger the association of NPD and BP.

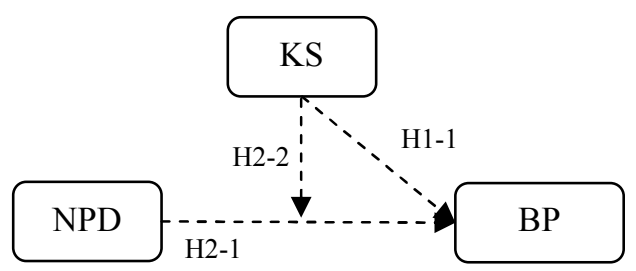

Fig. 1. Proposed conceptual model

The three constructs (i.e. KS, NPD and BP) and the relevant survey instruments associated with these hypotheses were operationalised based on previous empirical research studies $[6,12,13]$.

\section{RESEARCH DESIGN}

The research design predominantly follows a deductive approach, which begins with an abstract, logical relationship between concepts, then moves toward solid empirical evidence [14]. The purpose of this study is hypothesis testing, which offers a cross-sectional design to enhance understanding on the influence of KS activities on the effectiveness of NPD in achieving desired BP. The study was conducted mainly via a quantitative-based questionnaire survey applied comparatively across several companies. Thus, a questionnaire survey was deemed appropriate as an intial step to evaluate the ability of the conceptual model in representing the situational context among Taiwanese electronic manufacturing companies. In addition, survey research can be greatly improved when used in conjunction with other qualitative research methods, particularly case studies [15]. Therefore, a number of case studie were conducted after the empirical study to provide further insight into the specific nature of KS moderating effects on business activities and performance. As a result, the research was designed as a mixed method study combining sequential quantitative and qualitative data collection and analysis phases.

The first phase involved statistical analysis on collected questionnaire survey data solicited from electronic manufacturing companies in Taiwan. In particular, hypotheses testing utilised correlation and moderated regression analysis as the relationship verifier. This process resulted in greater understanding on the nature and extent of the influence of KS practices in leveraging heightened performance from NPD practices, resulting in higher levels of BP. To strengthen the statistical findings, a second phase qualitative study was conducted with the view to confirm the results obtained from the first phase and derive in-depth insight into the phenomena investigated.

Generally, case studies can be classified as descriptive, exploratory and explanatory: descriptive case studies focus on determining what needs to be described; exploratory case studies usually focus on theory and/or hypothesis development; and explanatory case studies focus on theory and/or hypothesis testing [16]. For the purpose of this study an explanatory case study approach was adopted since the purpose of this phase of research was to validate the results from the empirical study. To validate the empirical results, a qualitative "pattern matching" technique was employed whereby patterns of the observed values for each construct/factor identified from the case studies were compared with those predicted (hypothesised) in the model $[16,17]$.

\section{DATA ANALYSIS AND RESULTS}

\section{A. Phase 1: Empirical Study}

To provide statistical support for the research hypotheses, gathered data were analysed using a number of statistical techniques such as data examination, factor analysis, correlation and regression analysis processed through SPSS version 15.0 standard procedures. The survey was conducted in Taiwan from December 2007 to March 2008. Sample companies were chosen by randomly selecting a number of electronics manufacturing companies from the Taiwan Stock Exchange Centre (TSEC). In total, 550 survey packages containing a questionnaire, an introductory letter, an incentive and a pre-paid reply envelope were sent out via postal mail and/or delivered in person. Of the 550 surveys sent, 170 usable questionnaires were returned thus achieving a response rate of $30.9 \%$. The responses were considered a good representation of the opinions of the population, since the majority of the respondents were middle-aged, well-educated, experienced, and knowledgeable about product development and management in their companies. Data screening techniques were applied to all variables to ensure that the data complies with the assumptions of normality and linearity $[18,19]$.

Correlation and regression analyses were employed for analysing the relationships between the concepts. Correlation analysis showed that the NPD and KS concepts were positively associated with the BP concept, with Pearson correlation $r$ (coefficient of correlation) values ranging from 0.609 to 0.366 (significant at 0.01 level). Simple regression analyses revealed that NPD could be used to predict the variance of BP. Multiple regression analyses with interaction term $\left(\mathrm{NPD}^{*} \mathrm{KS}\right)$ were performed to investigate the effect of NPD on BP at different levels of KS (i.e., low, medium, high). The overall model validity ( $\mathrm{F}$ test) and the population 
correlation coefficient (t-test) of the derived regression models were significant at the 0.01 level [20]. In order to minimise multicollinearity, the independent variables (IVs) were centered and the NDP*KS term was formed by multiplying together the two centred terms [22]. The 170 cases in the data file satisfied the minimum sample size of 120 for supporting the case-to-IV ratio of 40 to 1 required by stepwise regression analysis with three IVs [21].

The simple regression models in Table I revealed that NPD could explain the variance of BP by $32.6 \%$ (with power of 0.80 ), thereby supporting hypotheses $\mathrm{H} 2-1$ that NPD is positively associated with BP.

TABLE I

REGRESSION MODELS

\begin{tabular}{cccccc}
\hline Hypotheses & Significant regression models & $R$ & $R^{2}$ & $\begin{array}{c}\text { Adj. } \\
R^{2}\end{array}$ & $F$ \\
\hline $\mathrm{H} 1-1$ & $\mathrm{BP}=1.316+0.565^{* *} \mathrm{KS}$ & 0.609 & 0.371 & 0.367 & $99.07^{* *}$ \\
\hline $\mathrm{H} 2-1$ & $\mathrm{BP}=1.523+0.439 * * \mathrm{NPD}$ & 0.574 & 0.330 & 0.326 & $82.57^{* *}$ \\
\hline $\mathrm{H} 2-2$ & $\mathrm{BP}=3.193+0.319 * * \mathrm{NPD}$ & 0.641 & 0.411 & 0.404 & $58.28^{* *}$ \\
& $+0.745^{*} \mathrm{NPD} \cdot \mathrm{KS}$ & & & & \\
\hline
\end{tabular}

Notes: **: significant at 0.01 level; *: significant at the 0.05 level.

Table I also reveals that in comparison with the simple regression models, the multiple regression model with interaction term had larger predicting power over the variance of BP. In particular, the combination of KS and NPD*KS could explain $40.4 \%$ of the variance in BP, which was much larger than NDP could predict as a single IV. The simple regressions in Fig. 2 indicate a significant ( $\alpha=0.05)$ positive regression of BP on NPD for all three levels of KS. The higher the KS level, the steeper the slope. This explains that KS has a stronger influence on the relationship between NPD and BP. The finding reveals the critical role of KS in leveraging NPD functions to enable the achievement of heightened business performance. The regression analysis with interaction terms upholds the hypotheses H2-2, that the higher the $\mathrm{KS}$, the stronger the positive association of NPD with BP.

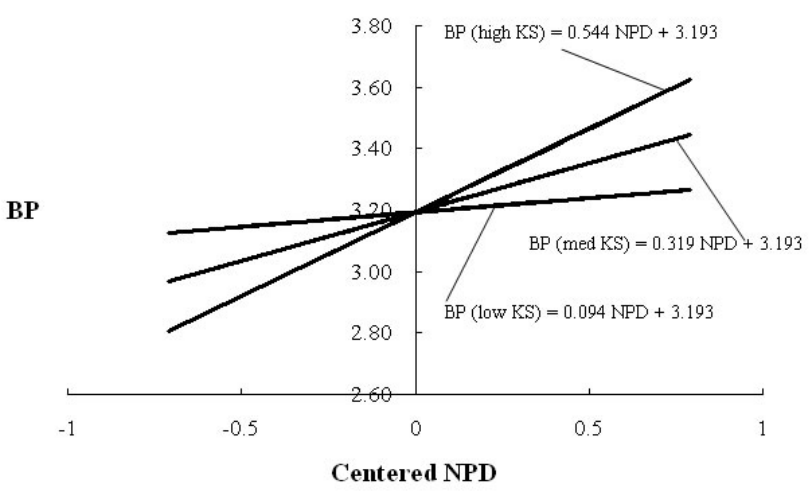

Fig. 2. Regression of BP on NDP at different level of KS

\section{B. Phase 2: Qualitative Study}

Following the results from the quantitative analysis, the predicted patterns (see Figure 3 and 4) were interpreted and developed based on the case studies. Three main patterns were developed using high, medium and low values for the proposed constructs.

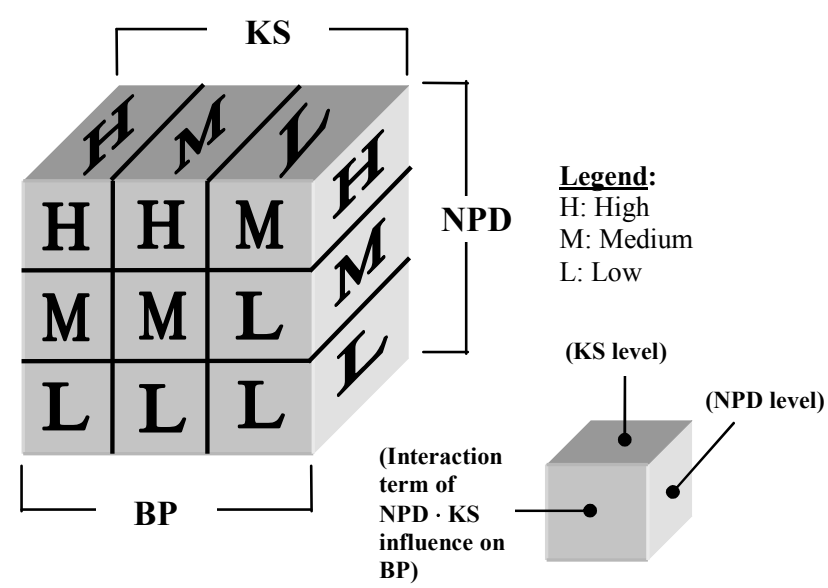

Fig. 3. Construct interaction term (KS·NPD onto BP) pattern matrix

\begin{tabular}{|c|c|c|c|}
\hline Hypotheses & \multicolumn{3}{|c|}{ Predicted patterns } \\
\hline H1-1 & $\mathrm{KS}$ & & $\mathrm{BP}$ \\
\hline $\begin{array}{l}\text { PP_KS1 } \\
\text { PP_KS2 } \\
\text { PP_KS3 }\end{array}$ & $\begin{array}{l}\text { High } \\
\text { Medium } \\
\text { Low } \\
\end{array}$ & & $\begin{array}{l}\text { High } \\
\text { Medium } \\
\text { Low } \\
\end{array}$ \\
\hline H2-1 & NPD & & $\mathrm{BP}$ \\
\hline $\begin{array}{l}\text { PP_NPD1 } \\
\text { PP_NPD2 } \\
\text { PP_NPD3 }\end{array}$ & $\begin{array}{l}\text { High } \\
\text { Medium } \\
\text { Low } \\
\end{array}$ & & $\begin{array}{l}\text { High } \\
\text { Medium } \\
\text { Low } \\
\end{array}$ \\
\hline $\begin{array}{l}\text { H2-2 } \\
\text { (Interaction term: }\end{array}$ & & $\mathrm{KS}$ & \\
\hline NPD $\cdot$ KS patterns) & NPD & $\dot{v}$ & $\mathrm{BP}$ \\
\hline PP_NPD·KS1a & (High & • High) & High \\
\hline PP_NPD·KS1b & (Medium & - High) & Medium \\
\hline PP_NPD.KS1c & (Low & · High) & Low \\
\hline PP_NPD·KS2a & (High & - $\quad$ Medium) & High \\
\hline PP_NPD·KS2b & (Medium & - $\quad$ Medium) & Medium \\
\hline PP_NPD·KS $2 c$ & (Low & - $\quad$ Medium) & Low \\
\hline PP_NPD·KS3a & (High & · Low) & Medium \\
\hline PP_NPD·KS3b & (Medium & · Low) & Low \\
\hline PP_NPD.KS3c & (Low & - Low) & Low \\
\hline
\end{tabular}

Fig. 4. Predicted patterns representing empirical models

Case studies were conducted with two electronics manufacturing companies in Taiwan. Company A provides 4C products (i.e. computing, communication, consumer electronics and car electronics) to the market with multinational offices and factories around the world. Company B supports OEM and ODM services for network storage solution, disk to disk backup, network data storage. Four and three members from the companies 
A and B, respectively, agreed to participate in the case studies. Semi-structured, face-to-face interviews were carried out to solicit opinions from the participants. An interview guide was developed and used during the interview session. Each interview was tape-recorded and transcribed. The contents of each interview were coded, summarised and tabulated to represent the value of each construct, which was rated against the developed criteria. In addition, secondary sources of information including newsletters and online documents published on a web site were obtained from each company and were analysed to complement the interview findings. Table II presents the final results of the case studies in terms of the patterns of the observed constructs and how they match the predicted patterns.

TABLE II

CASE STUDY RESULTS

\begin{tabular}{|c|c|c|c|c|}
\hline \multirow{2}{*}{ Company } & \multicolumn{3}{|c|}{ Constructs } & \multirow{2}{*}{ Hypotheses Match } \\
\hline & NPD & KS & BP & \\
\hline A & High & High & High & $\begin{array}{l}\text { H1-1: PP_KS1 (perfect match) } \\
\text { H2-1: PP_NPD1 (perfect match) } \\
\text { H2-2: PP_NPD·KS1a (perfect } \\
\text { match) }\end{array}$ \\
\hline B & Medium & High & Medium & $\begin{array}{l}\text { H1-1: PP_KS1 (partial match) } \\
\text { H2-1: PP_NPD2 (perfect match) } \\
\text { H2-2: PP_NPD·KS1b (perfect } \\
\text { match) }\end{array}$ \\
\hline
\end{tabular}

According to Table II, the pattern of relationships between the observed constructs of company A matches the predicted patterns of PP_KS1, PP_NPD1 and PP NPD.KS1a. At company A, the level of NPD (high) indicates a strong correlation with the level of BP (high). As predicted, the level of KS (high) appears to act as a moderating role, which in turn leverages the level of BP (high). This potential causal relationship was corroborated by interviewees' comments from most of the senior managers and engineers that employee involvement, design simplification and modular design have a strong impact on business competitiveness, manufacturing performance and process efficiency. They all agreed that $\mathrm{KS}$ is an essential and integrated business practice, which has helped in strengthening product development activities thus generating competitive capabilities which ultimately lead to improved business performance.

In addition, the relationships between constructs of company $\mathrm{B}$ indicate the predicted patterns of PP_KS1 (partial match), PP_NPD2 and PP_NPD·KS1b. The level of NPD (medium) has positively correlated with the level of BP (medium), but a high level of KS alone has not been sufficient to provide a high level of BP. As indicated in the interaction term pattern matrix, a high level of KS will not be able to sufficiently leverage the relationship between NPD and BP. This demonstrates that NPD activities must be functioning effectively before KS can leverage them. Moreover, whilst the KS construct was rated high with excellent IT infrastructure and support systems there were some lower performing KS activities such as the lack of managers and employee's efforts to promote learning and sharing of useful resource and knowledge. One of the company's project engineers stated that the company was addressing this deficiency through seeking out more effective practices to circulate such resources and knowledge within the company.

\section{DISCUSSION}

Results from empirical analysis supported the study hypotheses, thus demonstrating that NPD activities integrated with advanced knowledge sharing practices will likely to leverage business performance outcomes. This highlights the critical role that knowledge sharing plays as a management/process promoter. Specifically, effective IT infrastructure, systems support, open communication environment, and learning and sharing centres can help in stimulating and motivating employees' involvement whilst creating a knowledge-oriented culture to circulate and foster beneficial resource/knowledge constantly. This will, in turn, enhance their competitive capability, improve operation and management performance which ultimately leads to turnover, sales and profit growth; thereby strengthening the overall business performance.

Regarding the results from the case studies, it appears that for Company A the relationship can be used to adequately explain the moderating effect of knowledge sharing on new product development activities to achieve heightened business performance in a real work setting. In the case of Company B, the pattern matching exercise also supported the moderated relationship. Considering that the empirical study did not investigate the contribution of the various other operational factors contributing to $\mathrm{BP}$, as evident from the presence of unexplained variance in the moderated regression model, the degree to which the pattern of the observed constructs deviates from the pattern predicted by the model does not appear to be substantial. Reasonably, it can thus be concluded that the relationship derived from the quantitative analysis (Phase 1) was adequately supported by the findings from the case studies (Phase 2).

\section{CONCLUDING REMARKS}

This paper presents a study provided evidence to support the hypotheses that KS has a moderating effect upon the relationship between NPD and BP within the context of electronic manufacturing companies operating in Taiwan. In particular, the study highlighted the possible outcomes achievable by those manufacturing companies that promote and share their digested 
knowledge, from both internal and external sources, in the form of leveraged NPD activities and the subsequent BP. The study was carried out using a mixed method design integrating questionnaire survey and explanatory case study research. The hypothesis testing process, utilising moderated regression analysis, indicated that KS practices play an important role in enhancing NPD and other manufacturing operations and significantly leverage the relationship between NPD and BP. More importantly, the findings suggests that to promote KS practices effectively, a company should place a strong emphasis on establishing robust IT infrastructure, supportive systems, an open communication environment, as well as a user-friendly learning and sharing platform. Despite the findings demonstrating the leveraging power of $\mathrm{KS}$ on manufacturing operations such as NPD, these operations must be at a certain maturity level to ensure that any integrative KS activities are exploited to their fullest degree. Finally, through an explanatory case study approach, the relationships were validated by two cases of Taiwanese manufacturing companies. The case studies provided evidence that sufficiently explained the pattern of moderated relationships between constructs.

\section{REFERENCES}

[1] K. L. Choy, W. B. Lee, C. W. Lau, and L. C. Choy, "A knowledge-based supplier intelligence retrieval system for outsource manufacturing", Knowledge-Based System, vol. 18, pp. 1-17, 2005

[2] S. L. Ahire and P. Dreyfus, "The impact of design management and process management on quality: an empirical investigation", Operations Management, vol. 18, pp. 549-575, 2000.

[3] N. O. Ndubisi, M. Jantan, L. C. Hing, and M. S. Ayub, "Supplier selection and management strategies and manufacturing flexibility", Enterprise Information Management, vol. 18, no. 3, pp. 330-349, 2005.

[4] C. L. Tan and M. A. Vonderembse, "Mediating effects of computer-aided design usage: from concurrent engineering to product development performance", Operations Management, vol. 24, pp. 494-510, 2006.

[5] K. W. L. Antonio, R. C. M. Yam, and E. Tang, "The impacts of product modularity on competitive capabilities and performance: An empirical study", International Journal of Production Economics, vol. 105, pp. 1-20, 2006.

[6] K. C. Tan, V. R. Kannan, R. B. Handfield, and S. Ghosh, "Supply chain management: an empirical study of its impact on performance", Operations \& Production Management, vol. 19, no. 10, pp. 1034-1052, 1999.

[7] R. Lubit, "Tacit knowledge and knowledge management: The keys to sustainable competitive advantage", Organisational Dynamics, vol. 29, no. 4, pp. 164-178, 2001.

[8] S. B. Modi and V. A. Mabert, "Supplier development: Improving supplier performance through knowledge transfer", Operations Management, vol. 25, pp. 42-64, 2006.

[9] H. A. Artail, "Application of KM measures to the impact of a specialized groupware system on corporate productivity and operations", Information \& Management, vol. 43, pp. 551-564, 2006.
[10] V. Peltokorpi and E. Tsuyuki, "Knowledge governance in a Japanese project-based organization", Knowledge Management Research \& Practice, vol. 4, pp. 36-45, 2006.

[11] P. Ingram and T. Simons, "The transfer of experience in groups of organizations: implications for performance and competition", Management Science, vol. 48, no. 12, pp. 1517-1533, 2002.

[12] B. Fynes, and S. D. Burca, "The effects of design quality on quality performance", International Journal of Production Economics, vol. 96, no. 1, pp. 1-14, 2005.

[13] K. J. Petersen, R. B. Handfield, and G. L. Ragatz, "Supplier integration into new product development: coordinating product, process and supply chain design", Operations Management, vol. 23, pp. 371-388, 2005.

[14] W. L. Neuman, "Social research methods: qualitative and quantitative approaches", Fifth Edition, Allyn and Bacon, 2003.

[15]G.G. Gable, "Integrating case study and survey research method: an example in information systems", European Journal of Information Systems, vol. 3, no. 2, pp. 112-126, 1994.

[16] R. K. Yin, "Case study research: Design and Methods", Third Edition, SAGE Publications, Thousand Oaks, 2003.

[17]G. J. Nicholson and G. C. Kiel, "Can directors impact performance? A case-based test of three theories of corporate governance", Corporate Governance, vol. 15, no. 4, pp. 585-608, 2007.

[18] S. J. Coakes, "SPSS: analysis without anguish: version 12.0 for Windows", John Wiley \& Son Australia , Ltd, 2005.

[19] J. Pallant, "SPSS survival manual: a step by step guide to data analysis using SPSS for windows: version 10 for Windows", Allen \& Unwin, St Leonards, N.S.W., 2001.

[20] B. L. Bowerman, R. T. O'Connell, and D. A. Dickey, "Linear statistical models", Duxbury Press, Boston, 1986.

[21]B. G. Tabachinick, and L. S. Fidell, "Using multivariate statistics", Fourth Edition, Allyn and Bacon, 2001. 